\title{
DEEP VEIN THROMBOSIS: REVIEW AND UPDATE
}

\author{
Naba Kumar Pattnaik¹, Prasanna Kumar Mishra ${ }^{2}$
}

${ }^{1}$ Consultant, Cardiothoracic Surgeon, Department of Cardiothoracic Surgery, Apollo Hospital, Bhubaneswar. ${ }^{2}$ Consultant, Anaesthesiology, Department of Anaesthesia, Apollo Hospital, Bhubaneswar.

\section{ABSTRACT}

\section{BACKGROUND}

Deep vein thrombosis is a common occurrence encountered as a complication in post-operative period. Diagnosis of thrombosis and thromboembolism has taken a new turn with advent of newer investigating techniques. Use of ultrasound Doppler and other relevant blood tests has helped in evaluating peripheral venous and arterial blood flow, which was previously unavailable. One of the lifethreatening complication of Deep Vein Thrombosis is Pulmonary Embolism (PE), which can occur early and may be fatal. Recurrent deep vein thrombosis and post-phlebitic syndrome are other complications. So the early and correct evaluation of patients who are at high risk, proper management is necessary for better health care.

\section{KEYWORDS}

Deep Vein Thrombosis, Venous Thromboembolism, Pulmonary Embolism, Post-Thrombotic Syndrome.

HOW TO CITE THIS ARTICLE: Pattnaik NK, Mishra PK. Deep vein thrombosis: review and update. J. Evolution Med. Dent. Sci. 2016;5(103):7605-7610, DOI: 10.14260/jemds/2016/1719

\section{INTRODUCTION}

Deep Vein Thrombosis (DVT) is the formation of blood clot (Thrombus) within a deep vein, predominantly in legs. Less common site includes upper extremities, pelvis and abdomen. Together DVT and PE constitute a single disease process known as thromboembolism. Pulmonary thromboembolism is a life-threatening condition. Each year in USA 300,000 to 600,000 people get a blood clot in lungs.

In 1856, German pathologist Rudolf Virchow postulated the interplay of three processes resulting in venous thrombosis known as Virchow's Triad. They are decreased blood flow rate (Venous Stasis), tendency to clot (hypercoagulability) and endothelial damage of blood vessels. DVT formation typically begins inside the valves of the calf vein, where the blood is relatively oxygen deprived, which activates certain biochemical pathways for clot formation. The annual incidence of DVT is in between 69 to 139 cases per 100,000 people in general population,(1) whereas in hospitalised patients it is 350 per 100,000 admissions.(2) In another study, it has been observed that one in every nine persons develop DVT when younger than 80 years and clinically recognised VTE account for one of every twenty deaths in those older than 50 years.(3) The incidence is rare in children with less than one in 100,000 a year. For unknown reasons people of Asian descent have a lower VTE risk than whites. $(4)$

\section{Symptoms}

Leg swelling generally occurs because of an abnormal accumulation of fluid in the tissue of lower extremities. Other symptoms include leg pain, numbness, redness, itching, rash, ulceration of skin, shortness of breath and warm skin.

Financial or Other, Competing Interest: None.

Submission 21-11-2016, Peer Review 14-12-2016,

Acceptance 21-12-2016, Published 26-12-2016.

Corresponding Author:

Dr. Naba Kumar Pattnaik,

Plot No. 1211/C, Sector-6 CDA,

Bidanasi, Cuttack-753014.

E-mail:drnkpattnaik.ctvs@gmail.com

DOI: 10.14260/jemds/2016/1719

\section{(c) (i) $(\Theta$}

\section{Who is at Risk of DVT}

Age - DVT occurs more commonly in people who are over 50 years of age.

\section{Surgery}

DVT is a major risk associated with surgery. The risk of development of DVT is about $70 \%$ after non-elective HIP surgery, $48 \%$ after elective orthopaedic surgery, $12 \%$ after elective General Surgery; $50 \%$ of all deaths in orthopaedic surgery is due to PE.(5) Major gynaecological pelvic surgery poses DVT risk that is similar or higher than the risk involved in general abdominal surgery $(15 \%-40 \%)$ without prevention therapy. Open urological procedure confer DVT risk, but transurethral resection does not.

\section{Pregnancy}

Pregnancy is a natural hypercoagulable state in general. In post-partum state, placental tearing releases the substances that favour clotting. Oral contraceptives and hormonal replacement therapy increases the risk through varieties of mechanism including altered blood coagulation protein levels and reduced fibrinolysis.(6) The risk of thrombosis continues until about 6 weeks of post-natal period.

\section{Prolonged Immobilisation}

Immobilisation increases the risk of DVT,(7) long hospital stay, paralysis, when the leg is still for long period the calf muscles do not contract to help blood circulate which can increase the risk of blood clot. Immobilisation can cause DVT in $10 \%$ of all bed rest patients and $25 \%$ to $30 \%$ of ICU patient and patients with orthopaedic cast.

\section{Cancer}

Some form of cancer increases the amount of substances in blood, which cause the blood to clot. Cancer treatment with chemotherapy increases the risk of DVT and PE, probably by reducing circulating anticoagulant as an antithrombin III or protein C or S. Spontaneous DVT without any obvious cause is an important marker for possible occult malignancy. In about $38 \%$ cases of concomitant malignancy and DVT, the DVT is detected first. 


\section{Anaesthesia}

General anaesthesia increases the risk of DVT as compared to epidural/regional anaesthesia for the same procedure. Therefore, epidural or regional anaesthesia is preferred in lower limb orthopaedic surgery such as fracture neck of femur or arthroplasty in the elderly patients.

\section{Obesity}

Overweight of more than $20 \%-25 \%$ of expected weight increase the risk of DVT. Overweight puts more pressure on the legs and pelvis. ${ }^{(8)}$

\section{Cardiac Disease}

Congestive cardiac failure and Acute Myocardial Infarction (AMI) has greater risk for DVT and PE. Patients with AMI who is not on anticoagulant therapy has $26 \%$ - 38\% increased risk of DVT development.

\section{Chemotherapy}

Malignancy, chemotherapy, Vit K deficiency, oral anticoagulant use, surgery, intravascular coagulopathy can trigger an acquired deficiency of protein $\mathrm{C}$. In patients with severe liver disease, there may be antithrombin III deficiency. If antithrombin III level is reduced to half of the normal circulating level, the patient is at high risk of DVT.(9)

\section{Oral Oestrogen Therapy}

Studies show patients on oral oestrogen have about 5 to 10 times higher risk for developing DVT.(10)

\section{Inflammatory Bowel Disease}

Bowel diseases such as Crohn's disease or ulcerative colitis increase the risk of DVT.(11)

\section{Sitting for a Long Periods of Time}

Such as long driving and flying, when your leg remains still for many hours calf muscle does not contract which normally help blood to circulate, as such blood clot may occur.

\section{Inherited}

Antithrombin deficiency,(12) protein-C deficiency,(12) protein-S deficiency (type I),(13) dysfibrinogaemia(14) are some of the inherited factor that may contribute to development of DVT and PE. Factor V Leiden increases the risk of DVT more than it does for PE, a phenomenon referred to as the Factor V Leiden paradox.(15) Non 0- blood type is present in around 50\% of general population and varies with ethnicity and it is present in about $70 \%$ of those with VTE.(15)

\section{Mixed}

There are certain mixed factors that are responsible for DVT. A) Low free protein, B) Activated protein resistance, C) High Factor VIII level,(16) D) Hyperhomocysteinaemia, E) High Fibrinogen level and F) High Factor XI.

\begin{tabular}{|c|c|c|}
\hline & Clinical Parameter & Score \\
\hline 1 & $\begin{array}{c}\text { Active cancer treatment ongoing } \\
\text { or within 6 months or palliative care }\end{array}$ & +1 \\
\hline 2 & $\begin{array}{c}\text { Paralysis, paresis or recent plaster } \\
\text { immobilisation of lower extremities }\end{array}$ & +1 \\
\hline 3 & $\begin{array}{c}\text { Recently bed ridden for more than 3 } \\
\text { days or a major surgery within 4 weeks }\end{array}$ & +1 \\
\hline
\end{tabular}

\begin{tabular}{|c|c|c|}
\hline 4 & $\begin{array}{c}\text { Localised tenderness along } \\
\text { distribution of deep vein system }\end{array}$ & +1 \\
\hline 5 & Entire leg swollen & +1 \\
\hline 6 & $\begin{array}{c}\text { Calf swelling (measured at } \\
10 \mathrm{~cm} \text { below tibial tuberosity) } \\
\text { by more than } 3 \text { cms in comparison to } \\
\text { asymptomatic leg }\end{array}$ & +1 \\
\hline 7 & Pitting oedema & +1 \\
\hline 8 & Collateral superficial veins & +1 \\
\hline 9 & $\begin{array}{c}\text { Alternate diagnosis (as likely } \\
\text { or greater than that of DVT) }\end{array}$ & +1 \\
\hline \multicolumn{3}{|c|}{ Table 1. Wells Score for Prediction of DVT } \\
\hline
\end{tabular}

Well PS, Anderson DR, Bormanis J et al; "Value of assessment of pre-test probability of Deep Vein Thrombosis in clinical management. Lancer (1997). 317: 1795-1798).

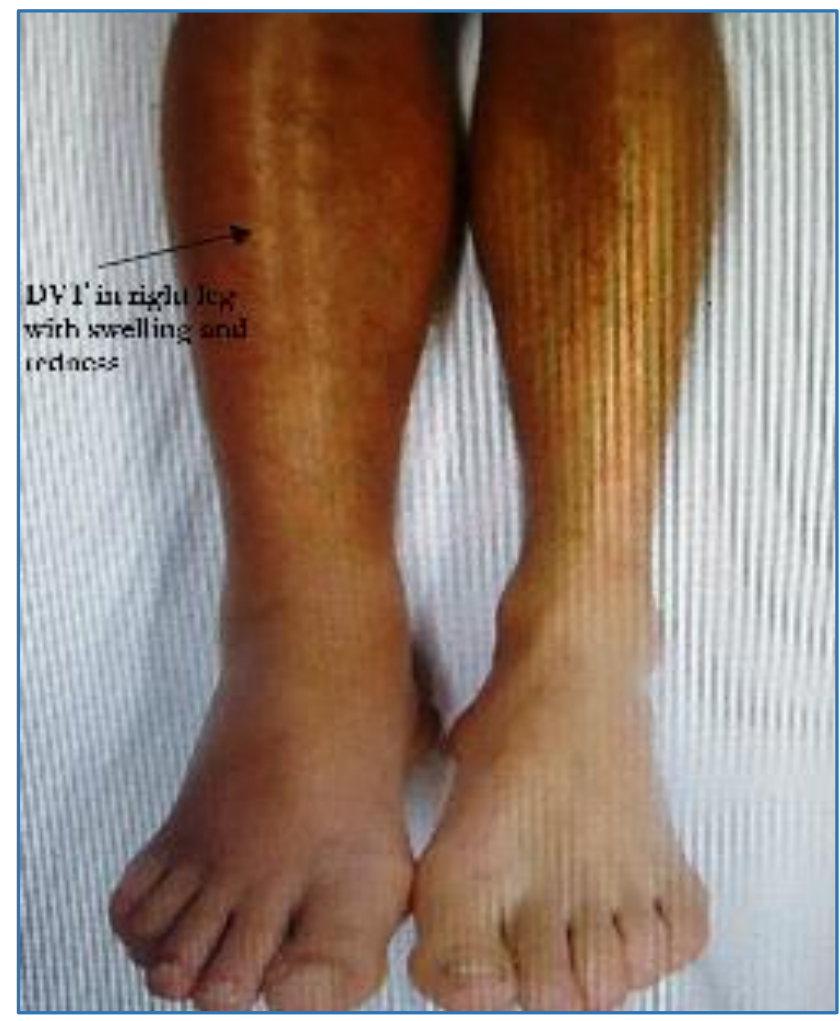

Figure 1. DVT in Right Leg with Swelling and Redness

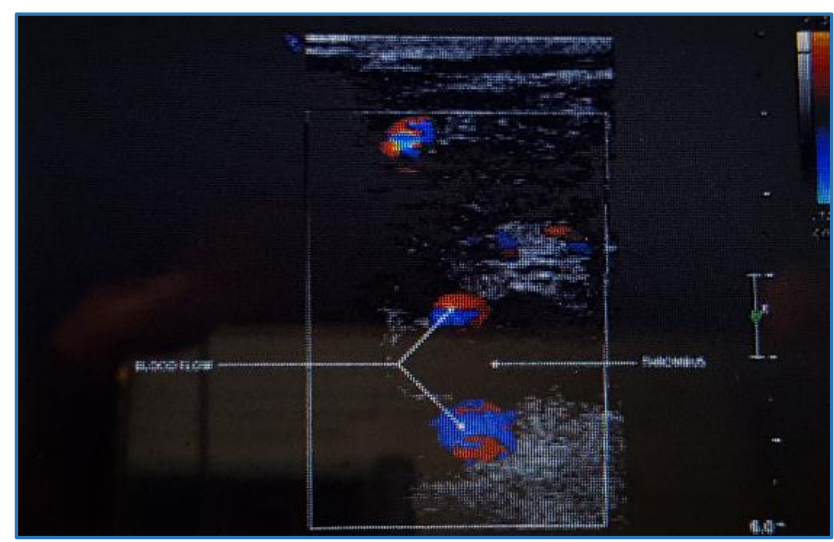

Figure 2. Cross-Section View of the Popliteal by Compression Ultrasonography Vein showing Partial Obstruction of the Vessel Lumen 


\section{Diagnosis}

\section{Signs and Symptoms}

The clinical diagnosis of DVT is often very difficult. Symptoms such as leg swelling, leg pain, tenderness, oedema, redness and ulceration of skin are typically associated with DVT (Figure 1), but the condition may only be definitely diagnosed with objective diagnostic tests such as compression ultrasonography, venography, Magnetic Resonance Imaging (MRI).(17) Some people are not aware of a deep vein clot until they have signs and symptoms of $\mathrm{PE}$, which includes unexplained shortness of breath -

- $\quad$ Pain with deep breathing.

- Coughing of blood. PE.

Rapid breathing and fast heart rate also may be a sign of

\section{Clinical Possibility Score}

One of the commonly used clinical scoring for evaluating the probability of DVT was developed by Wells and Colleague.(18) This tool quantifies the likelihood of an individual patient having DVT based on their history and physical examination. Therefore, the clinical judgement plays a critical role in diagnosis of DVT. Wells score for prediction of DVT (Table 1). The prediction is high with a score of 3 or more, moderate with a score of 1 - 2 and low score is zero.

Although, a high Well score indicates a clinical probability of DVT, an objective imaging technique such as compression ultrasonography, computed tomography, venography or MRI must be used to confirm or rule out DVT.

\section{INVESTIGATION}

\section{Compression Ultrasonography}

(Figure 2) It is also called venous ultrasonography or ultrasound, which is widely used for evaluation of suspected DVT.(19) It is a safe, non-invasive test that involves compressing and imaging femoral vein down to most proximal calf vein.(20) This test has inability to distinguish between old and fresh thrombus. However, it is acceptable when combined with score based clinical variable.

\section{Duplex Ultrasound (DUS)}

It is a non-invasive investigation performed for detecting venous anatomy, occlusion site and combination of real time B-ultrasonography with pulse Doppler. Barnes et al(21) described the technique to evaluate DVT at posterior tibial, popliteal, superficial femoral and common femoral vein. An attention should be made to keep the limb in normal anatomical position. DUS measures the velocity of blood flow in veins in normal situation, which can be affected by respiration and manual compression of foot and calf. In case of DVT, there will be abnormality in the flow of blood. It has $90 \%$ sensitivity and specificity in symptomatic patients.

\section{Computed Tomography Venography}

CT venography detect both distal and proximal DVT. It is invasive, painful and expensive. This test is reserved for indirect CT venography, which can be done at the same time as CT pulmonary angiography.(22)

\section{Magnetic Resonance Imaging (MRI)}

This non-invasive study is used to diagnose DVT unlike CT venography. MRI does not involve exposure to radiation. It is useful in diagnosing thrombosis of superior and inferior vena cava and pelvic veins. Its use can be limited by a long examination time and lack of access to equipment.(23)

\section{D-Dimer Measurement}

D-dimer is a protein segment produced by thrombus degradation that is formed when plasmin dissolves the fibrin strands that holds the thrombus together.(24) This test is performed on blood obtained from patient's fingertip. D-dimer blood test vary in their accuracy. However, this highly sensitive D-dimer test has high negative predictive value (that is to say if the results are negative, DVT is unlikely).(25) D-dimer concentration may be increased in normal pregnancy.

\section{Iodine 125 Fibrinogen Uptake (FUT)}

It is an invasive investigation and is now seldom used. The principle of this test is to inject radioactive fibrinogen intravenously and its uptake in fibrin clots is monitored. If there is $20 \%$ or more uptake, it is an area of thrombus. FUT has a sensitivity of $73 \%$ and specificity of $71 \%$ for symptomatic and asymptomatic DVT.(26)

\section{Risk Factor for Recurrence}

DVT is associated with a cumulative risk of VTE, recurrence of approximately $21 \%$ within 5 years of initial event.(27) Three important risk factors were identified and quantified in the Vienna prediction model.(28)

A. Initial Proximal (rather than Distal) DVT.

B. Male Gender.

C. Elevated D-Dimer Dimension.

Short term (rather than long term) duration of anticoagulation therapy is also associated with recurrence. A D-dimer concentration above $250 \mathrm{ng} / \mathrm{mL}$ measured three weeks after discontinuation of anti-coagulation is associated with 3.1 fold increased risk of VTE recurrence at two years. (29)

\section{Treatment of DVT}

DVT treatment is aimed at preventing the clot being bigger in size as well as from breaking loose and migrating to other part of the body, particularly to pulmonary bed causing PE. Patients should be advised to take bed rest and the affected limb should be elevated above the level of heart till the tenderness and oedema subsides.

\section{Blood Thinner}

Anticoagulants prevent both propagation and activate the endogenous lysis of the thrombus. Heparin is the initial therapy, which is available in either unfractionated heparin or Low Molecular Weight Heparin (LMWH). Initially, injection Heparin is administered 10,000 IU per hour as a bolus dose followed by continuous infusion of $1000-1500 \mathrm{IU} /$ hour. The dose is adjusted by keeping the PTT level two times the control value.

LMWH is also effective and better than unfractionated heparin, because the incidence of thrombocytopenia (a dreaded complication of Heparin) is less. Varieties of LMWH is available for use and the doses vary. It is administered subcutaneously in fixed doses, adjusted for body weight and without laboratory monitoring. LMWH like dalteparin (Fragmin) $200 \mathrm{IU} / \mathrm{kg}$ daily. Enoxaparin 1 to $1.5 \mathrm{mg} / \mathrm{kg}$ daily is commonly prescribed. 


\section{Warfarin}

(Coumarin); It is a vit $\mathrm{K}$ antagonist and is given once a day orally, starting while the patient is still on heparin and is continued for 3 to 6 months. It is better to overlay the injection Heparin with anticoagulant warfarin for at least 4 - 5 days. The reason behind is anticoagulation effect of warfarin is delayed. The dose of warfarin is adjusted to maintain the prothrombin time at an INR level of $2-3$. Warfarin may be ineffective if DVT is caused by cancer, so in cancer LMWH alone is used for 6 months after the thrombotic event.(30) Warfarin is not used in pregnant women.

Treatment with blood thinner usually lasts for 6 months.

\section{The following Situation may change the Length of Treatment}

1. If blood clot occurs after a short term risk (for example surgery), the treatment time is shorter.

2. If the blood clot is before the treatment time with blood thinner, is longer.

3. In patient diagnosed with cancer and DVT, the blood thinners are to be used for a longer period till persistence of the disease.

The most common side effect of blood thinner is bleeding. Bleeding occurs if the medicine thins blood too much. Sometimes the bleeding is internal and more disturbing if it occurs into the brain.

Patients treated with blood thinners must have their blood tested and monitored with PTT and INR. Heparin induced bleeding can be controlled with Protamine sulfate in titrated doses. FFP (Fresh Frozen Plasma) is used to combat the bleeding from blood thinner.

\section{Thrombolytic Therapy}

Direct thrombolysis by clot-bursting catheter is done.

- If the patient has a large clot causing pain.

- High risk case for PE.

- Have DVT in the arm rather than leg.

This procedure quickly break up the clot, but is riskier than taking blood thinner. Complications like bleeding occurs in 5\% - $10 \%$ of cases and stroke is likely. Under x-ray screening guide, a thin catheter is put into the vein and the tip of it into the DVT, then the drug (thrombolytic agent) is injected directly into the clot. The drug is called Tissue Plasminogen Activator (TPA). The European Society of Cardiology (ESC) Guidelines also recommend rescue thrombolytic therapy for patient with high risk of PE whose haemodynamic condition deteriorated.(31)

\section{Vena Caval Filter}

IVC (Inferior vena cava) filter is a small cone shaped device that is implanted in the inferior vena cava just below the level of kidney. This device catches blood clots of 5 microns and above and stops them from moving to different parts. Blood passed through the filter normally.

\section{Surgery}

Surgery to remove blood clot is rare. It is only considered if the blood clot is very large and is blocking a major blood vessel. Surgery also increases the risk of forming blood clots.

\section{Venous Thrombectomy}

Venous thrombectomy is indicated in patients with DVT whose symptoms are severe and have been present for fewer than 7 days. Other indications are,

1. Severe DVT.

2. Patients who could not be treated with thrombolysis and anticoagulation therapy.

3. DVT that has not responded to anticoagulation therapy.

4. Patients who are pregnant.

A catheter is inserted either in femoral vein in groin or popliteal vein below knee. Contrast dye is injected and venography done to identify the location of clot. Percutaneous thrombectomy is done by inserting a guide wire and advanced beyond the clot. A device at the tip of the catheter, either a mechanical tool or a high velocity jet breaks up the clot.

In case when the clot is non-occlusive the patient presents with pulmonary embolism; without leg signs thrombectomy will give excellent result.

\section{Caval Thrombectomy}

Venous thrombectomy via inferior vena cava is indicated in severe venous insufficiency approaching gangrene, particularly if the iliofemoral occlusion is bilateral. Early and aggressive surgery is done in such severe cases and holds out the only chance of arresting the disease and its consequence.

\section{Caval Ligation}

The aim of surgery in iliofemoral or caval venous thrombosis is to control embolism and to restore patency so that function is maintained. Therefore, the interruption of the main venous channel above the profunda termination is to be avoided if possible. The routine use of such technique as ligation and plication will lead to severe morbidity. In surgical management of over three hundred cases of iliofemoral venous thromboembolism caval ligation has been carried out in seven instances with a fatal outcome in 4 patients.

\section{Surgery in Pulmonary Embolism}

Surgical intervention in PE (weather associated with sign of venous thrombosis or not) depends totally on localising the site of venous thrombosis. For the peripheral segment, this is best achieved by iodine labelled fibrinogen technique. It is always essential to know the condition of the iliofemoral segment in planning the surgical approach. Because in iliofemoral venous thrombosis weather occlusive or nonocclusive embolism is a frequent complication, while in peripheral thrombosis embolism is much less frequent and less serious.

\section{Prophylaxis}

The findings of Endorse survey(32) suggest a need for hospital wise strategy to ensure appropriate preventive care for all patients at risk of DVT. The optional duration of anticoagulation needed to prevent VTE is an important aspect of care.

- In surgical patients, the risk of VTE remains high and persists after hospital discharge, particularly after hip replacement surgery. The 2012 American College of Chest Physician (ACCP) guideline recommends thromboprophylaxis for a minimum period of 10 - 14 days after knee or hip replacement surgery and suggests extending 
thromboprophylaxis in the outpatient period for up to 35 days from the day of surgery.(33)

- In non-surgical patients, thromboprophylaxis is usually administered for 6 to 14 days and although there is evidence that the risk of VTE may persist beyond this time the benefit of extended thromboprophylaxis have not been shown to outweigh the risk of bleeding. (34)

Approved Anti-Coagulant for VTE (for immobilised medical patient Table 2)

\begin{tabular}{|c|c|c|c|c|}
\hline & Drug & Target & Dose & $\begin{array}{l}\text { Name of } \\
\text { the Trial }\end{array}$ \\
\hline 1 & $\begin{array}{c}\text { UFH Un- } \\
\text { Fractionated } \\
\text { Heparin }\end{array}$ & $\begin{array}{c}\text { Factor } \\
\text { X-a and } \\
\text { Thrombin } \\
\text { (Indirect } \\
\text { via AT) }\end{array}$ & $\begin{array}{c}5000 \text { IU } \\
\text { BID to TID } \\
\text { Subcutaneously }\end{array}$ & \\
\hline 2 & $\begin{array}{l}\text { LMWH } \\
\text { Low } \\
\text { Molecular } \\
\text { Weight } \\
\text { Heparin } \\
\end{array}$ & $\begin{array}{l}\text { Factor X-a } \\
\quad \text { and } \\
\text { |Thrombin } \\
\text { (Indirect } \\
\text { via AT) }\end{array}$ & $\begin{array}{c}\text { Enoxaparin s/c } \\
\text { Injection } \\
20-40 \mathrm{mg} / \mathrm{OD} \\
\text { given for } \\
6-14 \text { days }\end{array}$ & $\begin{array}{c}\text { Medinox } \\
\text { Trial(35) }\end{array}$ \\
\hline 3 & Fandaparinux & $\begin{array}{l}\text { Factor X-a } \\
\text { (Indirect } \\
\text { via AT) }\end{array}$ & $\begin{array}{c}\text { S/c Injection } \\
2.5 \mathrm{mg} / \mathrm{OD} \\
\text { given for } \\
6-14 \text { days }\end{array}$ & $\begin{array}{l}\text { Artemis } \\
\text { Trial(36) }\end{array}$ \\
\hline \multicolumn{5}{|c|}{$\begin{array}{c}\text { Table 2. DVT Prophylaxis - Anticoagulant } \\
\text { Doses: Medinox and Artemis Trial }\end{array}$} \\
\hline
\end{tabular}

\section{Anti-Platelet for Prevention of VTE}

Although aspirin/ASA (Acetylsalicylic Acid) is more effective than placebo for preventing VTE in high risk patients, it appears to be less effective than LMWH. The 2012 ACCP guidelines recommends ASA, among other anti-thrombotics over no prophylaxis at all, but LMWH or oral anti-coagulants are preferred.

\section{Compression Stocking}

These help prevent swelling associated with deep vein thrombosis. Elastic stockings are worn on the leg from feet to the above knee level usually in the day time. Compression stockings are routinely used in critical care setup for prevention of DVT in high risk patients. They also lower the chance of developing post-thrombotic syndrome.

\section{Complications of DVT}

Pulmonary Embolism (PE) is a frequent and serious complication of DVT. Perfusion lung scanning has detected approximately $50 \%$ of documented DVT patients and asymptomatic venous thrombosis is found in $70 \%$ of patients with confirmed clinically symptomatic PE. Other complications associated with VTE include post phlebitic syndrome and recurrent thromboembolism. Post phlebitic syndrome occurs in about $25 \%$ of cases and almost $30 \%$ of patients with DVT develop post phlebitic syndrome after 20 years of followup. The diagnosis of post-thrombotic syndrome can be made out on clinical picture of leg pain and swelling, which may mimic with acute recurrence of DVT and confirmed by MRI. Recurrent DVT occurs in about $20 \%$ of patients at 5 years and $30 \%$ after 10 years of followup.

\section{CONCLUSION}

\section{A Vision for Future}

There is no shortage of interest with the problem of DVT. High profile individuals and organisations with substantial resources are committed to the task. The key for the stake holders is to come together to build a co-ordinated plan that can lead to dramatic reduction in the incidence and burden of these disease in this nation.

\section{The call to action is for all who can have an impact on the} incidence and burden of DVT and PE

- The public at large is knowledgeable about the risk of factors triggering events, and symptoms of these diseases and individual feel empowered to talk with their clinicians about them whenever appropriate.

- Evidence based practice for the screening, prevention, diagnosis and treatment of DVT/PE are clearly understood and routinely applied by all medical professional in all settings.

- New scientific evidence is routinely being discovered to fill gaps in knowledge, and these findings are quickly and easily disseminated to the public and put into practice by health professionals.

The overall result of action agenda will be to save tens of thousands of life each year and to reduce the suffering of many more. Implementing the vision is not an easy task and progress will take time. Many barriers stand in the way, but solution must be found and more importantly set into motion. Energy and concomitant of individual families, the health care system, private sector organisation and Government is headed at all levels to work together to build solution that will bring health and name to our nation. With these dedicated efforts, we can make the vision a reality.

\section{REFERENCES}

1. Silverstein MD, Heit JA, Mohr DN, et al. Trends in the incidence of deep vein thrombosis and pulmonary embolism: a 25 year population based study. Arch Intern Med 1998;158(6):585-93.

2. Proctor MC, Greenfield LJ. Pulmonary embolism: diagnosis, incidence and implications. Cardiovasc Surg 1997;5(1):77-81.

3. Havig 0. Deep vein thrombosis and pulmonary embolism. An autopsy study with multiple regression analysis of possible risk factors. Acta Chir Scand Suppl 1977;478:1120.

4. Zakai NA, McClure LA. Racial differences in Venous thrombo embolism. J Thromb Haemost 2011;9(10): 1877-82.

5. Geerts WH, Berggvist D, Pineo GF, et al. Prevention of Venous thrombo embolism. American college of chest physicians evidence-based clinical practice guidelines ( $8^{\text {th }}$ edn). Chest 2008;133(Suppl 6):381S-453S.

6. Reitsma PH, Versteeg HH, Middeldorp S. Mechanistic view of risk factor for venous thromboembolism. Arterioscler Thromb Vasc Biol 2012;32(3):563-8.

7. Lapostolle F, Surget V, Borron SW, et al. Severe pulmonary embolism associated with air travel. North Eng J of Med 2001;345(11):779-83.

8. Rosendal FR, Reitsma PH. Genetics of venous thrombosis. J Thromb Haemost 2009;7(Suppl 1):301-4 
9. Bovill EG, van der Vliet A. Venous valvular stasisassociated hypoxia and thrombosis: What is the link? Annual Rev Physiol 2011;73:527-45.

10. Blanco-Molina A, Monreal M. Venous thrombo embolism in women taking hormonal contraceptives. Expert review of Cardiovascular Therapy 2010;8(2):211-5.

11. Tichelaar YI, Kluin-Nelemans HJ, Meijer K. Infections and Inflamatory diseases as risk factors for venous thrombosis. A systematic review. Thrombo Haemost 2012;107(5):827-37.

12. Martinelli I, Bucciarelli P, Mannucci PM. Thrombotic risk factors: basic pathophysiology. Crit Care Med 2010;38 (Suppl 2):S3-S9.

13. Lijfering WM, Rosendaal FR, Cannegieter SC. Risk factors for venous thrombosis - current understanding from an epidemiological point of view. $\mathrm{Br} \mathrm{J}$ Haematol 2010;149(6):824-33.

14. van Langevelde $K$, Flinterman LE, van Hylckama VA, et al. Broadening the factor $\mathrm{V}$ Leiden paradox: pulmonary embolism and deep-vein thrombosis as two sides of the spectrum. Blood 2012;120(5):933-46.

15. Jenkins PV, Rawley O, Smith OP, et al. Elevated factor VIII level and risk of venous thrombosis. $\mathrm{Br} \mathrm{J}$ Hematol 2012;157(6):653-63.

16. Blann AD, Lip GY. Venous thrombo embolism. BMJ 2006;332(7535):215-9.

17. Well PS, Anderson DR, Bormanis J, et al. Value of assesment of pretest probability of deep vein thrombosis in clinical management. Lancet 1997;350(9095):1795-8.

18. Trupie AGG, Chin BSP, Lyp GYH. Venous thrombo embolism, pathophysiology, clinical features and prevention. BMJ 2002;325(7369):887-90.

19. Stern JB, Abehsera M, Grenet D, et al. Detection of pelvic vein thrombosis by magnetic resonance angiography in patients with acute pulmonary embolism and normal lower limb compression ultra-sonography. Chest 2002;122(1):115-21.

20. Barnes RW, Russell HG, Wu KK, et al. Accuracy of Doppler ultrasound in clinically suspected venous thrombosis of the calf. Surg Gynecol Obstet 1976;143(3):425-28.

21. Saad WE, Saad N. Computed tomography for venous thromboembolic disease. Radiol Clinic North America 2007;45(3):423-45.

22. Kluge K, Muller P, Strunk J, et al. Experince in 207 combined MRI examination for acute pulmonary embolism and deep vein thrombosis. KJR Am J Rongenon 2006;186:1686-96.

23. Adam SS, Key NS, Greenberg CS. D-dimer antigen: current concepts and future prospects. Blood 2009;113(13): 2878-87.

24. Wells PS, Kovacs MJ, Bormanis J, et al. Expanding eligibility for outpatient treatment of deep vein thrombosis and pulmonary embolism with low molecular heparin. Arch Interrn Med 1998;158(16):1809-12.
25. Comerota AZ, Katz ML, Grossi R J, et al. The comparative value of non-invasive testing for diagnosis and surveillance of deep vein thrombosis. J Vasc Surg 1988;7(1):40-9.

26. Hansson PO, Sorbo JE, Eriksson H. Recurrent venous thrombo embolism after deep vein thrombosis: incidence and risk factors. Arch Int Med 2000;160(6):769-74.

27. Eichinger S, Heinze G, Jandeck LM, et al. Risk assessment of recurrence in patients with unprovoked deep vein thrombosis for pulmonary embolism, the Vienna prediction model. Circulation 2010;121(14):1630-6.

28. Eichinger S, Minar E, Bialonczyk C, et al. D-dimer level and risk of recurrence venous thrombo embolism. JAMA 2003;290(8):1071-4.

29. Geerts WH, Pineo GF, Heit JA, et al. Prevention of venous thrombo embolism: the Seventh ACCP conference on antithrombotic and thrombolytic therapy. Chest 2004;126(Suppl 3):338S-400S.

30. Cohen AT, Tapson VF, Bergmann JF, et al. Venous thromboembolism risk and prophylaxis in the acute hospital care setting (ENDORSE study): a multinational cross-sectional study. Lancet 2008;371(9610):387-94.

31. Falck-Ytter, Francis CW, Johanson NA, et al. Prevention of VTE in orthopedic surgery patient: anti-thrombotic therapy and prevention of thrombosis, $9^{\text {th }}$ edn. American college of chest physicians evidence based practice guidelines. Chest 2012;141(Suppl 2):e278S-e325.

32. Hull RD, Schellong SM, Tapson VF, et al. Extended duration vrnous thrombo embolism prophylaxis in acutely ill medical patients with recently reduced mobility: a randomized trial. Ann Intern Med 2010;153(1):8-18.

33. Samama MM, Cohen AT, Darmon JY, et al. A comparision of enoxaparine with placebo for the prevention of venous thromboembolism in acutely ill medical patients. Prophylaxis in medical patients with enoxaparin study group. N Eng J Med 1999;341(11):793-800.

34. Cohen AT, Davidson BL, Gallus AS, et al. Efficacy and safety of fandaparinux for the prevention of venous thromboembolism in older acute medical patients: randomized placebo control trial. BMJ 2006;332(7537): 325-9.

35. Kartikeyan G, Eikelboom JW, Turpie AG, et al. Does Acetyl Salycylic acid (ASA) has a role in prevention of venous thromboembolism? Br J Hematol 2009;146(2):142-9.

36. Mohr DN, Silverstein MD, Heit JA, et al. The venous stasis syndrome after deep venous thrombosis or pulmonary embolism: a population based study. Mayo Clin Proc 2000;75(12):1249-56. 